CLINICAL ETHICS

\title{
Risk and supervised exercise: the example of anorexia to illustrate a new ethical issue in the traditional debates of medical ethics
}

\section{S Giordano}

$J$ Med Ethics 2005;31:15-20. doi: 10.1136/jme.2003.004812

Sport and physical activity is an area that remains relatively unexplored by contemporary bioethics. It is, however, an area in which important ethical issues arise. This paper explores the case of the participation of people with anorexia nervosa in exercise. Exercise is one of the central features of anorexia. The presence of anorexics in exercise classes is becoming an increasingly sensitive issue for instructors and fitness professionals. The ethics of teaching exercise to anorexics has, however, seldom, if ever, been addressed. Codes of ethics and legislation do not offer guidelines pertinent to the case and it is left unclear whether anorexics should be allowed to participate in exercise classes. It is shown by this paper that there are strong ethical reasons to let anorexics participate in exercise classes. However, the paper also explains why, despite these apparently cogent ethical reasons, there is no moral obligation to allow a person with anorexia to take part in exercise/sports activities.

\footnotetext{
Correspondence to: Dr S Giordano, Centre for Social Ethics and Policy (CSEP)/Institute of Medicine, Law and Bioethics (IMLAB), The University of Manchester, The School of Law, Williamson Building Oxford Road, Manchester M13 9PL, UK; simona. giordano@man.ac.uk
}

Accepted for publication 3 February 2004
S ports and physical activity represent one of the areas that have not yet been widely covered by bioethical reflection. Ethical issues often arise in sports and physical activity, issues which are, in important ways, similar to those often faced by healthcare professionals, but which present peculiarities that need to be addressed and explored.

Among the ethical conflicts that are more frequent in the context of sport and physical activity which are seldom discussed, are those raised by the participation of people who are for a variety of reasons unfit for a particular activity. A particular case is that of the participant with anorexia nervosa. The way anorexia raises problems and dilemmas in the context of physical activity is an interesting and compelling example of how the classic dilemmas of bioethics are increasingly found outside the boundaries of healthcare settings. The methods of bioethics will prove important in the articulation and resolution of the ethical dilemmas that occur in a context where people are neither professional nor personally expecting to meet ethical issues.

Anorexia and eating disorders generally are becoming an increasingly sensitive issue for sports and exercise instructors (I shall use the terms instructor, teacher, and trainer to refer to the person who teaches sport or exercise). ${ }^{1}$ A number of studies have analysed the relation between sports, exercise and anorexia. ${ }^{23}$ One of the most appealing types of exercise for people with anorexia is probably exercise to music (ETM), both because of its increasing popularity ${ }^{4}$ and for the following reasons:

- Exercise to music activities are mainly aerobic and therefore are best tailored for fat burning purposes;

- Classes are widely available and usually affordable to the general public;

- They are often "drop in classes": one can tour around different health clubs and different classes, thus hiding eventual overparticipation;

- The relationship between the teacher and the participant is normally impersonal and the goals of the participant are often unknown to the instructor;

- No medical certification is normally required;

- Given the impersonal character of the class, the person can "hide" in the group and hope to be unnoticed;

- In the group, the person with anorexia, who is likely to be, to a variable extent, debilitated, may find extra motivation to maintain the intensity of exercise at a high level.

Despite this, the ethics of teaching ETM to people with eating disorders has seldom, if ever, been addressed. This paper will set out to examine, for the first time, the ethical issues in teaching ETM to people with eating disorders. It will explore the ethical dilemmas that arise for the instructor in detail, using the methods of analytical investigation. I shall look at the relevant codes of ethics and pertinent legislation and will consider whether or not trainers have any ethical reason, or even a moral obligation, to allow the person with anorexia or another eating disorder to take part in their class.

\section{ANOREXIA, EXERCISE, AND RISKS FOR HEALTH}

One of the central clinical features of anorexia is physical activity. Exercise is a compensatory

Abbreviations: ATP, adenosine triphosphate; $\mathrm{COSHH}$, control of substances hazardous to health; ETM, exercise to music; $P A R-Q$, physical activity reactions questionnaire; $\mathrm{PPE}$, personal protective equipment regulations; RIDDOR, reporting of injuries, diseases and dangerous occurrences regulations. 


\section{Box 1}

Supervision of exercise in those at risk-the case of the eating disordered participant

- Exercise and sports may be life threatening for the person with an eating disorder.

- The participation of people with eating disorders in sports and exercise is an increasingly sensitive issue for exercise professionals, because of the spread of the disorder and the high rate of participation of eating disordered people in exercise.

- There are neither legislative nor professional standards to guide fitness and sports trainers in the decision as to whether to allow the eating disordered participant to take part in their class/activity.

- There are valid ethical reasons to allow an eating disordered person to participate in exercise and sport.

- These ethical reasons may be based both on the principle of respect for people's autonomy and on the principle of beneficence.

- Despite these ethical reasons, there is no ethical obligation to allow a person with eating disorders to take part in exercise and sport.

- While accepting a person who is unfit for a type of sport/physical activity can be seen in some circumstances, as a supererogatory act-such an act cannot be considered as an ethical obligation.

List of codes and regulations

Register of Exercise Professionals: Exercise and Fitness Coaching, Teaching and instructing Code of Ethics (http://www.exerciseregister.org)

RIDDOR-Reporting of Injuries, Diseases and Dangerous Occurrences Regulations 1995 (www.hse.gov.uk/pubns/ hse31.pdf)

COSHH-Control of Substances Hazardous to Health2002 (http://www.hse.gov.uk/hthdir/noframes/coshh/ index.htm)

PPE-The Personal Protective Equipment Regulations 2002

(SI 2002 No. 1144)-(www.hmso.gov.uk/stat.htm)

behaviour used by the person in order to burn stored fats and calories ingested through food and drink. ${ }^{5}$

Exercise is essential to weight loss/containment programmes, not only as it allows "calories and fat burning", but also because it alters body composition, appetite, and basal metabolism. ${ }^{6}$ Aerobic exercise is particularly relevant, as aerobic energy production utilises both carbohydrates and fats, and stored fats can only be burned through aerobic exercise. $^{7}$

Typically, people with anorexia will choose moderate to vigorous exercise, most commonly running, swimming, and callisthenics, ${ }^{8}$ including ETM classes. ${ }^{9}$

Although some people may mistakenly believe that these activities are "moderate" or "inherently safe" and that they "will do no harm", the risks associated with exercising with abnormal eating regimes may be very serious. ${ }^{10}$

The first important consequences of excessive reduction of body weight ${ }^{11}$ and of exercising in a state of malnutrition is loss of muscle mass and therefore debilitation. The malnourished person who takes exercise will in fact use up muscles to provide the fuel that cannot be provided by food or stored fats. ${ }^{12}$

A second consequence of low body weight is amenorrhoea. The lack of oestrogens linked to absence of menstrual periods causes bone thinning, even in the presence of hormone replacement (Mickley, ${ }^{12} \mathrm{p} 47$ ) This increases risks of fracture during exercise (Jack, p 309) and long term danger of osteoporosis. ${ }^{13-15}$

The effects of poor nourishment on the heart are particularly worrisome for the exercise instructor: the heart diminishes in size, as does any other muscle in the body, and becomes weaker. Low blood pressure is the normal outcome of this process, together with impairment in the ability of the heart to increase oxygen delivery to the tissues while exercising. The mitral valve may prolapse and potentially fatal arrhythmias may occur (Mickley, ${ }^{12}$ p 47 ; Jack, ${ }^{8}$ p 299)

Even in the absence of evident emaciation, abnormal nutrition and compensatory behaviour may have significant adverse effects on health. Vomiting usually produces electrolyte imbalance, which may cause cramps, which may be due to lack of adenosine triphosphate (ATP), one of the carriers of energy in human cells, and to low potassium levels (Jack, ${ }^{8}$ p 300) epileptic attacks, and severe abnormalities in heart rhythms, even respiratory paralysis (Mickley, ${ }^{12} \mathrm{p} 47$ ) cardiac arrest, and death (Jack, ${ }^{8}$ p 299). A major problem is that individuals with low potassium levels are often asymptomatic, and it is therefore impossible to predict when a potentially life threatening cardiac arrhythmia may occur. ${ }^{16}$ Thus, "underweight is physically dangerous, often in ways that are not apparent" (Mickley, ${ }^{12}$ p 47).

Does all this mean that trainers should not allow people who appear to have anorexia to take part in their class, or that they should ask for medical certification (with the result that the participant will probably not come back, as no serious physician would give certification to someone who had reached advanced levels of emaciation)?

One may wonder how the instructor would identify the person with anorexia. The anorexic may in fact be within acceptable parameters of body weight (Pargman, ${ }^{11}$ p 135) and, on the other hand, very thin people may not be anorexic. The instructor may, however, be familiar with the participant and may have noticed either a change in the exercise regime or a too rapid or excessive loss or change of weight. Moreover, people with anorexia normally exercise in a frenetic, ritualised, and rigid way, sometimes in the face of advanced emaciation, (Jack, ${ }^{8}$ p 299) something that the instructor will easily notice.

One may also argue that it is not up to the trainer to "rescue" all people who take exercise despite the fact that they should not do so. People often do not disclose their medical conditions to the teacher, and the teacher must accept that there is a degree of risk inherent in teaching exercise. While this argument may in certain circumstances be compelling, the fact that an instructor cannot "know everything" about her participants, and that there will always be people whose medical conditions will remain unknown to her, this is no justification for refusing to think about what she should do when she has reason to believe that the activity she is teaching is likely to harm some of her clients. It must be pointed out that there are cases in which the emaciation is so striking that any reasonable person would be concerned. In these cases, it would surely be appropriate for instructors to wonder whether they should allow these people to take part in their class, whatever the reasons might be for their physical state.

We should now look at the relevant codes of ethics and pertinent legislation, to see whether they provide any guidelines for instructors in these cases.

\section{CODES OF ETHICS}

The ETM trainer's conduct must be in conformity with Exercise and Fitness Coaching, Teaching \& Instructing Code of Ethics. ${ }^{17}$ The code of ethics does not provide much help in 
relation to issues raised by the anorexic participant; indeed the guidelines ever appear to conflict and ultimately to leave full discretion to the trainers.

Under the heading Relationships, the Code reads:

\section{1: The good coach will be concerned primarily with the wellbeing, health, and future of the individual participant and only secondarily with the optimisation of perfor- mance. \\ 2.2: A key element in a coaching relationship is the development of independence. Participants must be encouraged to accept responsibility for their own beha- viour and performance when training. \\ 2.4: The relationship between the coach and participant relies heavily on mutual trust and respect.}

Under the heading Safety the Code reads:

\section{5: The participants should be made aware of their personal responsibilities in terms of safety.}

If any suggestions could be drawn from these guidelines, these would appear to be conflicting.

According to points 2.2, 2.4, and 9.5, the instructor should try to enhance the participant's independence, and encourage her/him to take responsibility for their behaviour. If these guidelines were to be applied to the case of teaching the anorexic, one might conclude that, once made aware of the risks for their own health, anorexics should be allowed to take exercise, if they still wanted to. This may be seen as an application of the doctrine of respect for individual autonomy, which is widely accepted in medical settings.

According to point 2.1, however, the instructor should be concerned primarily with the participant's wellbeing and health. This seems coherent with the general "paternalistic" approach that trainers are normally advised to adopt. In fact, it is, for example, suggested that well cushioned supportive shoes be considered compulsory, and that pregnant women should show written medical permission to the fitness instructor before being allowed to exercise (Egger, et al, ${ }^{7} \mathrm{pp}$ $116,168)$.

Legislation is also unclear as to the appropriate standard of care the ETM instructor should meet. In 1998 the American College of Sports Medicine recommended that instructors obtain a signed health questionnaire from participants (Physical Activity Readiness PAR-Q), which might also provide some form of legal protection in case of accident. There does not seem, however, to be any legal duty to undertake client health screening, at least in the UK, and in reality trainers often choose to verbally address the issue of whether there are medical conditions about which people would like to tell them (Dalgleish, et al, eds, ${ }^{4}$ pp 323, 141). As we shall see later, the assessment of the risk is understood to be one of the responsibilities of any fitness instructor, and this includes identification of people at risk. Given the nature of ETM classes, however, and the impersonal relationship between instructors and participants, proper health screening is unlikely to be attainable. The vast majority of classes are open to the public in the form of "drop in classes" and therefore written health screening would be impractical. Besides, a health screening is not a medical certificate: it need not follow any medical examination and the instructor has to rely on the word of the participant (whose knowledge of her/his health status may be incomplete, or who may be unwilling to disclose her/his medical condition). Thus, while health screening may provide some legal protection in case of accident, it has little value in terms of tailoring appropriate exercise and in terms of ethics of teaching. In other words, health screening may resolve any future legal problems, but it will not always resolve the moral dilemmas of the instructor.

Other regulations that are relevant to the ETM instructor are the Reporting of Injuries, Diseases, and Dangerous Occurrences Regulations, (RIDDOR) 1995; the Control of Substances Hazardous to Health Regulations, (COSHH), and the Personal Protective Equipment Regulations, (PPE) which are relevant especially for aqua instructors. None of these contain guidelines that may be pertinent to the case at issue in this paper.

The presence of an anorexic in an ETM class raises therefore a genuine ethical issue, which no legal regulation or deontological code may help to resolve. The next sections of the paper will explore the ethical reasons for allowing the anorexic person to participate in an ETM class.

\section{RESPECT FOR AUTONOMY: EATING DISORDERS AND EXERCISE}

It is generally understood that respect for people's autonomy and self determination is a moral imperative, except in cases where individual autonomy will impinge upon the autonomy and freedom of others. From this point of view, it may be argued that trainers should inform the participant of the risks involved in exercising in a state of emaciation, but once the participant has shown understanding of the risks, it is up them to decide whether to attend the class. This may be regarded as an application of the doctrine of respect for individual autonomy in the area of sports and physical activity.

Some will object that, in these cases, one cannot discuss "respect for autonomy". The desire to exercise, so the argument may go, is "a symptom" of anorexia, and as such cannot be autonomous. Consequently the only ethical option for the instructor is to treat anorexics in their best interests, usually against their wishes (paternalistically).

I cannot discuss this objection here $\mathrm{e}^{18-20}$ but let us suppose that the objection is valid and that anorexics should be treated in their best interests. Even if one takes this approach, important arguments would suggest that the instructor should allow anorexics to participate in the class.

\section{EATING DISORDERS AND MAXIMISATION OF LONG TERM HEALTH}

At first glance, it may appear that "paternalism" demands that instructors refuse to allow anorexics to take part in their classes. If, however, letting them into the class could be dangerous, turning them down could be even more dangerous.

In fact, a strong need for independence and control underlies anorexia, and openly "paternalistic" acts are normally discouraged. Paternalism toward anorexics has proved to increase the sense of lack of control that is characteristic of anorexics, and therefore to compromise long term recovery. ${ }^{21}$ The instructor who is primarily concerned with the long term health and safety of the participant thus has good reasons for allowing her to participate in the class. ${ }^{22}$

The instructor also has other good reasons to let anorexics participate in the class.

\section{EATING DISORDERS AND MINIMISATION OF HARM}

"Sir Karl Popper has suggested that we should concern ourselves ... with the minimisation of suffering. By 'suffering' we must understand misery involving actual pain, not just unhappiness". ${ }^{23}$ It has also been recognised that "in most cases we can do most for our fellow men by trying to remove their miseries" Smart, $^{23}$ p 30). Virtually all moral codes include some principle of non-maleficence, that is a principle of not harming, and of choosing the course of action that is least harmful. 
From the point of view of the minimisation of harm, the instructor also has reason to allow the anorexic to take part in the class.

The anorexic who is refused access to a class will probably not renounce exercise: she may instead go running, cycling or swimming ( $\mathrm{Jack}^{8}{ }^{8}$ 292-312). Exercise on an individual basis is probably overall more risky for the anorexic than an ETM class. The class is in fact generally structured in order for the participant to work within the aerobic threshold (average $40-70 \%$ of the person's maximal oxygen uptake, or $\mathrm{VO}_{2} \max$ ) (Egger, et al, pp 16, 116) and a number of methods (observation, music choice/pitch, talk test, perceived rate of exertion) may be used to monitor the participant's level of workout. Therefore ETM classes may be considered safer than other types of exercise, in which heart rate monitoring is not performed - or not performed by qualified personnel. Moreover, any class setting or sports centre will offer qualified personnel in case of emergency.

The conclusion is that both from the point of view of respecting people's autonomy/self determination and from the point of view of paternalism and beneficence, there are strong ethical reasons to allow the anorexic to take part in the activity.

\section{SUMMARY}

All these considerations may induce the instructor to believe that she has a moral obligation to accept anorexics in their classes, that she must accept them. Despite the fact that instructors may have apparently cogent reasons to accept eating disordered participants, they are not, however, morally obliged to do so. The next sections of the paper explain why instructors are not morally obliged to accept anorexics in their classes.

\section{WHY EATING DISORDERED PARTICIPANTS CHANGE THE NATURE OF THE INSTRUCTOR'S JOB}

So far, we have explored the importance of exercise for people with eating disorders; we have seen the risks involved in exercising for these people; and finally we have seen that there are important ethical reasons that may convince the teacher to allow the eating disordered person to participate in her exercise class, despite the risks for the health of that person. As we are now going to see, however, instructors do not have a moral obligation to allow a person with an eating disorder to take part in their exercise class.

The reasons why instructors are not morally obliged to permit people with eating disorders to participate in their classes have to do with the scope of ETM classes and with the competencies and responsibilities of the teacher.

Accepting a participant with eating disorders may be considered tantamount to accepting a different job, for three main reasons.

(1) The ETM class is a "customer service" (Dalgleish, et al, eds, ${ }^{4}$ p 332). This service may be described in many ways, given that people participate in exercise for a

\section{Box 2}

\section{Autonomy \\ Respect for the anorexic's own choices}

Beneficence (promotion/protection of welfare) Promotion of sense of self control and responsibility and therefore maximisation of long term health. Protection from more serious consequences that may follow exclusion from the class-exercise in solitude and without specialised supervision multitude of reasons and that the instructor, consequently, ends up selling an indefinite number of things. The central elements of this service consist, however, in "benefits for health", which may be summarised as follows:

- Improvements in cardiovascular capacity

- Improvements in muscular strength

- Improvements in flexibility

- Improvement in motor skills-coordination, speed, power, agility

- Improvements in posture

- Improvements in body awareness

- Changes in body composition

- Reduction in the risk of developing diseases, mainly heart diseases, diseases of insulin producing cells, arthritis, and osteoporosis (Dalgleish, et al, eds, ${ }^{4} \mathrm{pp}$ $7-8,12)$.

Unfortunately, as we have seen, exercise is not beneficial in this way for the anorexic and may even threaten her/his life. Although a perhaps bigger potential threat exists for the person outside the class, exercise in the class also puts the person at direct risk for his health and life. Thus, by accepting the person into her class the instructor renounces the selling of what she is supposed to sell-the benefits for health listed above-and accepts that she is working for goals that are alien to any appropriate understanding of her job.

(2) ETM classes are tailored for averagely healthy people. Specific classes are designed for particular groups (disabled, elderly people, children, pregnant women, etc), for which specific qualifications will be required. Therefore, the average ETM class is not appropriate for people whose health is average, and eating disordered or openly emaciated people may certainly be included in this group. Of course the trainer will probably be unable to spot all eating disordered people, as well as all people with other non-obvious or unknown conditions, and there will always be a degree of nonpreventable risk in exercise. In some cases, however, there is sufficient evidence that an individual cannot exercise safely, evidence that may be obtained by using basic observation skills.

(3) Finally, although there is no clear legal duty for the instructor to obtain medical certification or to proceed to client health screening, assessment of risk for the participant is understood to be one of the ethical responsibilities of the instructor. ${ }^{24}$ It has been suggested that if the instructor "had prior knowledge of an existing danger or risk but took no corrective action to help prevent resulting injuries, this failure to act would most likely constitute an extreme form of conduct" (defined as gross negligence, wilful and wanton conduct, or reckless conduct). ${ }^{25}$ The instructor who is willing to accept the anorexic into his class needs to be aware that she is thereby renouncing responsibilities which, although not enforced by law, are often regarded as responsibilities of all instructors as such, namely caring for the health and safety of participant in the class and during exercise. As we have seen above, the instructor may be persuaded to allow the anorexic to take part in the class in order to prevent her from harming herself outside the class in isolation or in order to prevent her from suffering long term harm resulting from violation of her capacity for self determination. By accepting the responsibility to care about what may happen to the person outside the class or in the future, 
however, the teacher partly renounces the responsibilities that are within the scope of her job, namely, caring for what may happen to the participant in the class and while exercising.

\section{WHY INSTRUCTORS ARE NOT MORALLY OBLIGED TO ALLOW EATING DISORDERED PARTICIPANTS TO TAKE PART IN THEIR CLASSES}

For these reasons, it seems that allowing the anorexic person to participate in the class amounts to accepting "a different job". When the person with anorexia enters the studio, she implicitly asks the teacher to enter into a new and atypical (implied) contract. The instructor who has reason to believe that the person has an eating disorder and who decides to allow her to take part in the class agrees, by so doing, to comply with a set of goals and responsibilities that are alien to the goals of the ETM class.

Indeed, as previous sections have shown, utilitarian considerations may lead the instructor to believe that this is the right thing to do. The instructor is not, however, obliged to do this. In fact, the transaction between instructor and participant is still a professional transaction, a type of "contract" or "customer service", and like any contract, it must be voluntarily entered into. Nobody can be obliged, much less morally obliged, to subscribe to tasks and responsibilities for which they do not possess relevant qualifications and which are in direct contradiction of the main aims of their job. From an ethical point of view, entering into these types of atypical contracts can be regarded as a "supererogatory act", but not as a "mandatory act". There cannot be a moral obligation for a fitness trainer to accept that she must instruct anyone who is likely to be harmed by the activity she is teaching, whatever may happen to that person outside the studio. Indeed, if fitness trainers are to remain committed to their proper function as fitness trainers, they have good reasons to reject the anorexic participant. We should also consider that the instructor who is concerned with what may happen to the participant outside the class may have other options-advice help lines, directing the participant to a specialised clinical psychologist, and/or discussing the risks for health with the participantthat do not involve direct hazard to the participant.

\section{CONCLUSIONS}

The participation of people with anorexia in fitness classes is a problem requiring sensitive handling which is becoming more widespread, given the increasing spread of eating disorders among young people, and the tendency of eating disordered people to participate in exercise classes (Thompson, ${ }^{1}$ p 26); (Dalgleish, et al, eds, ${ }^{4}$ p 237); (Jack, ${ }^{8}$ pp

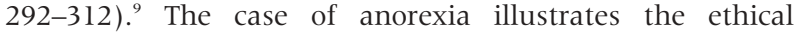
dilemmas that may arise for sports trainers and coaches as they pursue their profession. The instructor is faced with an ethical dilemma as to whether she should allow anorexic participants to take part in her classes. I have shown that there are strong ethical reasons that may persuade the instructor to let such people take part in her class. These reasons, however, do not amount to a moral obligation on the part of the instructor. Allowing the participant to take part in the class should be regarded as an agreement to enter an atypical contract, in which the instructor would accept as a part of her job, the obligation to comply with goals that are alien to any appropriate ETM class standards, and to accept responsibilities that go beyond her competencies. This transaction is not necessarily unethical, and may even be considered as a "supererogatory" act, on the part of the instructor. There is not, however, a moral obligation to enter into this type of contract with the anorexic participant, and in spite of the ethical reasons for allowing her to take part in the class, refusing to teach her is not unethical and is indeed compatible with the appropriate function of the ETM instructor.

The conclusions of this paper have broader implications, related to teaching sports and fitness to those at risk. Every sport-even sports that are not classified as extreme sportsinvolves a degree of risk (sport related injuries). In normal circumstances trainers should be aware of the risks inherent in the sport they teach. They should be able to maximise the benefits while minimising these risks. Instructors will be aware that risks cannot be eliminated. In normal circumstances, however, the benefits associated with sport and physical activity outweigh the risks and part of the job of the instructor is making sure that this is the case.

In many cases people, however, are of less than average health. They may have back problems, asthma, diabetes, knee injuries, or they may be pregnant. Participants may even be unfit for reasons unrelated to health (they may not have the appropriate equipment-appropriately cushioned shoes-for example). In these circumstances the risks are not inherently related to the sport. The risks are related to the physical condition of the participant and the choice of inappropriate equipment. The instructor will have to balance a number of variables in order to decide whether she should accept those participants. The instructor will have to consider the individual case on the basis of ethical principles (respect for participants' autonomy, protection/promotion of their health/ safety) and on the basis of a number of other factors. These factors include: evaluation of the risks of exercising with that particular condition; whether it is possible to tailor specific exercise programme for that particular individual; whether it is possible to monitor the exercise of that particular individual in a group situation; how many individuals at risk there are in the group, and whether it is possible for the instructor to monitor all of them at the same time, and so on. The instructor should be able to weigh up the balance between the risks and the benefits of the sport/exercise for that particular individual in those specific circumstances, and of course these will differ from one case to the next. Part of this assessment is based on communication with the client. The client should inform the teacher of her condition and a constructive programme should be tailored for that client.

The case of anorexia is different from these cases for a number of reasons. The eating disordered person is, first of all, unlikely to inform the instructor of her condition-if anything, she will hide it. No constructive communication is likely to take place.

Moreover, exercise is a part of the anorexic's condition, and the benefits of the sport/exercise are minimal compared to the risks for the health of the anorexic participant.

The instructor may have ethical reasons for agreeing to teach participants at risk. These reasons do not, however, entail an ethical obligation. The sport/fitness trainer has no ethical obligation to teach those at risk, however cogent the ethical reasons to do so may be.

\section{REFERENCES}

1 Thompson RA, Trattner SR. Helping athletes with eating disorders. Champaign: Human Kinetics Publishers, 1993:26.

2 Eisler I, Le Grange D. Excessive exercise and anorexia nervosa. Int J Eat Disord 1990:9:377-86.

3 Yates A, Shisslack $C$, Crago $M$, et al. Overcommitment to sport: is there a relationship to eating disorders? Clin J Sport Med 1994;4:39-46.

4 Dalgleish J, Dollery S, Frankham H, eds. The health and fitness handbook. London: Longman, 2001:237.

5 American Psychiatric Association. Diagnostic and statistical manual of mental disorders DSM-IV. Washington DC: APA, 2002: diagnostic category 307. 1. 6 Wilfley DE, Grilo CM, Brownell KD. Exercise and regulation of body weight. In: Shangold MM, Mirkin G, eds. Women and exercise, physiology and sports medicine. Philadelphia: Davis Company, 1994:33-4.

7 Egger G, Champion N, Bolton A. The fitness leader's handbook. London: A\&C Black, 2002:14, 18 
8 Jack L, Katz MD. Eating disorders. In: Shangold MM, Mirkin G, eds. Women and exercise, physiology and sports medicine. Philadelphia: Davis Company, 1994:292-312

9 Pruitt JA, Kappius RV, Imm PS. Sports, exercise, and eating disorders. In: Diamant L, ed. Psychology of sports, exercise, and fitness: social and personal issues. Washington: Hemisphere Publishing Corp, 1991: ch 7.

10 Davis C, Katzman DK, Kaptein S, et al. The prevalence of high level exercise in the eating disorders: etiological implications. Comp Psychiatry 1997;38:321-6.

11 Pargman D. Understanding sport behavior. Upper Saddle River: Prentice Hall, 1998:132.

12 Mickley DW. Medical dangers of anorexia nervosa and bulimia nervosa. In: Lemberg R, Cohn L, eds. Eating disorders, a reference sourcebook. Phoenix: Oryx Press, 1999:46.

13 Shelley R. Anorexics on anorexia. London: Jessica Kingsley Publishers, 1992:7.

14 Cuntz U, Frank G, Lehnert P, et al. Interrelationships between the size of the pancreas and the weight of patients with eating disorders. Int J Eat Disord 2000;27:297-303.

15 Marcos A. Eating disorders: a situation of malnutrition with peculiar changes in immune system. Eur J Clinical Nutrit 2000;54(suppl 1):61-4S.

16 Shisslak CM, Crago M. Eating disorders among athletes. In: Lemberg R, Cohn L, eds. Eating disorders, a reference sourcebook. Phoenix: Oryx Press, 1999: 79-83, at 81
17 http://www.exerciseregister.org/CodeofEthicalPractice.pdf (accessed 5 July 2004).

18 Giordano S. Addicted to eating disorders? The Italian Journal of Psychiatry $2001 ; 11: 73-7$

19 Giordano S. Qu'un souffle de vent... an exploration of anorexia nervosa. Med Humanit 2002;28:3-8.

20 Giordano S. Anorexia nervosa and refusal of nasogastric treatment. Bioethics 2003;17:261-78.

21 Selvini Palazzoli M, Cirillo S, Selvini M, et al. Ragazze anoressiche e bulimiche, la terapia familiare. Milan: Cortina, 1998:96-7

22 DiBartolo MP, Shaffer C. A comparison of female college athletes and nonathletes: eating disorder symptomatology and psychological wellbeing. JSEP 2002;24:33-41.

23 Smart JJC, Williams B. Utilitarianism: for and against. Cambridge: Cambridge University Press, 1996:28.

24 British Universities and Colleges Physical Education Association. Assessment of risk for student activities. Acrobat Reader Copyrights, 1978-1996. http:// www2.umist.ac.uk/sport/AU/Safety/BUCPEA/bucpeari.pdf (accessed 5 July 2004).

25 NSCA Professional Standards \& Guidelines Task Force. Strength \& conditioning: professional standards \& guidelines. Colorado Springs, $\mathrm{CO}$. NSCA 2001: 38. http://www.nsca-lift.org/Publications/standards.shtml (accessed 5 July 2004). 